\title{
Efeitos do glifosato sobre microrganismos simbiotróficos de soja, em meio de cultura e casa de vegetação
}

\author{
Juliano dos Santos Malty(1), José Oswaldo Siqueira ${ }^{(1)}$ e Fátima Maria de Souza Moreira ${ }^{(1)}$
}

(1)Universidade Federal de Lavras, Dep. de Ciência do Solo, Caixa Postal 37, CEP 37200-000 Lavras, MG. E-mail: jsmalty@ufla.br, siqueira@ufla.br, fmoreira@ufla.br

\begin{abstract}
Resumo - Os efeitos do herbicida Roundup, formulado à base de glifosato, foram avaliados sobre três estirpes de Bradyrhizobium elkanii (BR 29, INPA 80A e INPA 553A), e uma de B. japonicum (BR 86), e sobre três espécies de fungos micorrízicos arbusculares (FMA) (Gigaspora margarita, Glomus etunicatum e Scutellospora heterogama), em meios de cultivo com concentrações crescentes do herbicida ( 0 a $454 \mu \mathrm{mol} \mathrm{L}{ }^{-1}$ ); foram também avaliados os efeitos sobre a nodulação e micorrização da soja, em casa de vegetação, em solo que recebeu, antes da semeadura, doses do herbicida equivalentes a 1,25 até $10 \mathrm{~L} \mathrm{ha}^{-1}$. O Roundup mostrou-se inibitório ao crescimento de Bradyrhizobium spp. e aos fungos em meio de cultura, e esse efeito foi crescente com o aumento das concentrações aplicadas, tendo variado em razão das espécies ou estirpes avaliadas. No entanto, a inibição in vitro só ocorreu em concentrações muito superiores à dose recomendada para aplicações no campo. As estirpes BR 29, INPA 553A e INPA 80A mostraram-se mais tolerantes ao glifosato, em relação à estirpe BR 86. O efeito do herbicida sobre a germinação e o crescimento dos tubos germinativos dos esporos dos FMA foi diferenciado, tendo sido observada inibição decrescente de G. etunicatum para S. heterogama e G. margarita. A aplicação do herbicida ao solo, antes da semeadura, até a dose equivalente a $10 \mathrm{~L} \mathrm{ha}^{-1}$ não influenciou na nodulação e na colonização micorrízica da soja.
\end{abstract}

Termos para indexação: simbiose, fungos micorrízicos, Bradyrhizobium, nodulação.

\section{Effects of glyphosate on soybean symbiotic microorganisms, in culture media and in greenhouse}

\begin{abstract}
The effects of the Roundup herbicide on three strains of Bradyrhizobium elkanii (BR 29, INPA 80A and INPA 553A), one of B. japonicum (BR 86), and on three species of arbuscular mycorrhizal fungi (AMF) (Gigaspora margarita, Glomus etunicatum and Scutellospora heterogama), were evaluated in culture media containing increasing concentrations of the herbicide $(0-454 \mu \mathrm{M})$; evaluations were also made on the effects on nodulation and mycorrhiza colonization of soybean grown in a soil treated with Roundup doses equivalent to 1.25 to $10 \mathrm{~L} \mathrm{ha}^{-1}$ before sowing. The herbicide inhibited growth of Bradyrhizobium spp. and AMF in culture medium. These effects were directly related to increasing concentrations, and varied depending on the strain and species evaluated. However, in vitro inhibition occurred only when concentrations were greater than that recommended for use in the field. Strains BR 29, INPA 553A and INPA 80A showed to be more resistant to glyphosate, when compared to BR 86. Herbicide inhibition on germination and growth of AMF spore germ tubes decreased from G. etunicatum to $S$. heterogama and G. margarita. Soil application of Roundup before sowing up to a dose equivalent to $10 \mathrm{~L} \mathrm{ha}^{-1}$ had no effect on nodulation and mycorrhiza colonization of soybean.
\end{abstract}

Index terms: symbiosis, mycorrhiza, Bradyrhizobium, nodulation.

\section{Introdução}

O glifosato é um herbicida não seletivo, pós-emergente e de ação sistêmica, com elevada amplitude de utilização, em razão de sua alta eficiência, baixa toxicidade a animais e ao meio ambiente, destacandose entre os de maior volume comercializado no mundo (Cox, 2000).
A expansão do plantio direto e, mais recentemente, os avanços biotecnológicos que permitiram a comercialização de variedades geneticamente modificadas, tolerantes a este herbicida, como a soja, causaram o aumento do uso de herbicidas à base de glifosato nos agrossistemas, elevando assim a presença dessa molécula no ambiente, especialmente no solo (Siqueira et al., 2004). Isto traz preocupação, pois o uso generali- 
zado do glifosato pode contaminar o solo e a água e impactar os componentes bióticos do ecossistema, especialmente a microbiota do solo e simbiontes radiculares, como as bactérias fixadoras de nitrogênio atmosférico e os fungos micorrízicos arbusculares (FMA), os quais ocorrem invariavelmente associados às raízes da soja, exercendo grande influência na nutrição e sanidade dessa cultura.

Os impactos do glifosato na microbiota e os processos biológicos do solo têm sido bastante estudados, porém de forma indireta, com estudos que envolvem comunidades heterotróficas (Busse et al., 2001). Com raras exceções, esses estudos não revelaram efeito adverso prolongado deste herbicida no solo (Wardle \& Parkinson, 1990, 1991). Há relatos de efeitos inibitórios sobre microrganismos em meio de cultura (Quinn et al., 1988; Gorlach-Lira et al., 1997), havendo também casos de estímulo ao crescimento microbiano heterotrófico (Roslycky, 1982). Para bactérias fixadoras de nitrogênio em vida livre, os efeitos do glifosato variam muito em função das espécies estudadas (Haahtela et al., 1988; Santos \& Flores, 1995).

No caso de rizóbio, o crescimento, a sobrevivência, a nodulação e a atividade da nitrogenase têm sido avaliados em diversos trabalhos, que revelam resultados inconsistentes, e que variam de acordo com as doses aplicadas, espécies/estirpes estudadas e condições experimentais, como em meios artificiais (Faizah et al., 1980; Mallik \& Tesfai, 1983; Eberbach \& Douglas, 1989; Martensson, 1992; Moorman et al., 1992), ou em solos (Mallik \& Tesfai, 1985; Moorman, 1986). Recentemente, Santos et al. (2004) observaram respostas diferenciadas no crescimento de estirpes de Bradyrhizobium spp. nativas do Brasil, em razão da aplicação de diferentes formulações comerciais do glifosato, revelando a importância de se considerar os componentes adjuvantes desses herbicidas nessas avaliações de impactos. Em soja tolerante ao glifosato (Roundup Ready, RR), King et al. (2001) relataram que a aplicação do glifosato aumentou o número e diminuiu o peso dos nódulos.

Com relação aos FMA, pouco se conhece, pois se encontrou apenas um estudo sobre os efeitos do glifosato, o qual proporcionou aumento significativo da colonização micorrízica da soja (Morandi, 1989).

Neste trabalho, avaliou-se o efeito do herbicida Roundup (glifosato) sobre estirpes de Bradyrhizobium spp. e de FMA, em meio de cultivo com doses crescentes do herbicida, e sobre a nodulação e micorrização da soja, em solo que recebeu diferentes doses do herbicida.

\section{Material e Métodos}

Este trabalho constou de experimentos de laboratório em meio de cultura, e com solo em casa de vegetação, desenvolvidos no Departamento de Ciência do Solo (DCS), da Universidade Federal de Lavras (Ufla).

No primeiro experimento, quatro estirpes de Bradyrhizobium spp. foram avaliadas in vitro: BR 29 $(=29 \mathrm{~W}=$ SEMIA $5019-$ B. elkanii $)$ e BR 86 (= SEMIA 5080 = CPAC 7 - B. japonicum), recomendadas pela Relare como inoculantes para a cultura da soja, INPA 80 A (B. elkanii) e INPA 553A (B. elkanii), ambas isoladas de solos da Região Amazônica (Moreira et al., 1998) e, atualmente, mantidas na coleção do Laboratório de Microbiologia do Solo do DCS/Ufla.

As estirpes foram inicialmente cultivadas em meio 79 líquido composto, em g L ${ }^{-1}$, por: manitol, $10 ; \mathrm{K}_{2} \mathrm{HPO}_{4}$, 0,05; $\mathrm{MgSO}_{4}, 0,02 ; \mathrm{NaCl}, 0,01$; extrato de levedura, 0,4; e pH ajustado em 6,8 (Fred \& Waksman, 1928), sob agitação orbital constante a $110 \mathrm{rpm}$ e $28^{\circ} \mathrm{C}$, por seis dias. Depois do período de crescimento, $1 \mathrm{~mL}$ de cada cultura foi adicionado a frascos de Erlenmeyer com $72 \mathrm{~mL}$ de meio 79 líquido, acrescidos de 29, 58, 112 e $213 \mu \mathrm{mol} \mathrm{L}{ }^{-1}$ de Roundup (360 g L ${ }^{-1}$, do equivalente ácido de N-(fosfonometil) glicina - Glifosato) esterilizado em filtro e diluído em água estéril. A qualidade inicial do inóculo foi confirmada pela contagem das unidades formadoras de colônias (UFC), depois de diluições seriadas, que apresentou número acima de $8,79 \times 10^{8} \mathrm{UFC} \mathrm{mL}^{-1}$. Como tratamento testemunha empregou-se $72 \mathrm{~mL}$ de meio, sem adição do herbicida.

O experimento foi conduzido em delineamento experimental inteiramente casualizado, com três repetições para cada tratamento desenvolvidas por 120 horas sob agitação. Alíquotas de $5 \mathrm{~mL}$ foram retiradas de cada frasco de Erlenmeyer para determinação de densidade ótica, utilizando-se um espectrofotômetro marca Hitachi, modelo U-2001 UV/Vis, com leituras feitas a $560 \mathrm{~nm}$ de absorbância, considerando-se como padrão "0" aquele determinado em água destilada. Desenvolveu-se um segundo experimento, porém alterando-se as concentrações do herbicida no meio de cultura (58, 114, 230 e $454 \mu \mathrm{mol} \mathrm{L}^{-1}$ ) e o tempo de cultivo (72 horas).

Para o experimento com FMA, esporos de Gigaspora margarita, Glomus etunicatum e Scutellospora heterogama, oriundos de ecossistemas diversos do Estado de Minas Gerais e mantidos na coleção de FMA do DCS/Ufla, foram extraídos do solo, conforme metodologia de Gerdemann \& Nicolson (1963), seleci- 
onados e plaqueados em ágar-água $1 \%$, vertidos em placas de Petri com 0,0, 25,6, 51,0, 102,0, 204,5 e 409,0 $\mu \mathrm{mol} \mathrm{L}{ }^{-1}$, do equivalente ácido de $\mathrm{N}$-(fosfonometil) glicina, fornecidos a partir de uma solução de Roundup esterilizado em filtro e diluído em água estéril. Cada dose representou um tratamento com quatro repetições, cada uma constituída por uma placa com dez esporos. Depois da transferência dos esporos, as placas foram vedadas com filme de plástico, envolvidas em papel alumínio e incubadas em sala de crescimento a aproximadamente $28^{\circ} \mathrm{C}$, por 15 dias. Ao final da incubação, procedeu-se à avaliação da porcentagem de germinação e crescimento do tubo germinativo dos esporos, utilizando-se sistema de categorias, atribuindo-se valores de 0 a 4 , sendo 0 : sem crescimento; $1:<5 \mathrm{~mm} ; 2: 5$ a $10 \mathrm{~mm}$; $: 10$ a $15 \mathrm{~mm}$ e 4: >15 mm.

Num terceiro experimento, realizado em casa de vegetação, no período de maio a julho de 2003, avaliou-se a aplicação prévia de Roundup ao solo, sobre o crescimento, nodulação e micorrização da soja (Glycine max (L.) Merril), variedade Doko melhorada, semeada em um Latossolo Vermelho distrófico (LVd), muito argiloso, coletado no bairro Jaguara, no Município de Nazareno, MG. Depois de peneiramento, o solo recebeu calagem, tendo apresentado $\mathrm{pH}$ em água $=6$; $\mathrm{P}$ e K (Mehlich-1), 1,4 e $74 \mathrm{mg} \mathrm{dm}^{-3}$, respectivamente; $\mathrm{Ca}^{2+} \mathrm{e}$ $\mathrm{Mg}^{2+}(\mathrm{KCl} 1 \mathrm{~N}), 3,8$ e $1,8 \mathrm{cmol}_{\mathrm{C}} \mathrm{dm}^{-3}$, respectivamente e $\mathrm{MO}\left(\mathrm{Na}_{2} \mathrm{Cr}_{2} \mathrm{O}_{7} 4 \mathrm{~N}+\mathrm{H}_{2} \mathrm{SO}_{4} 10 \mathrm{~N}\right), 2,7 \mathrm{dag} \mathrm{kg}^{-1}$.

Em vasos com capacidade de $1,5 \mathrm{~kg}$, foi colocado cerca de $1 \mathrm{~kg}$ de solo sem FMA, nos dois terços inferiores dos vasos, e $0,5 \mathrm{~kg}$ de um solo infestado com FMA aplicado no terço superior, como fonte de inóculo. O solo infestado continha esporos de Glomus etunicatum, Gigaspora margarita e Glomus occultum, em densidade média de 4 esporos $\mathrm{mL}^{-1}$ de solo. Depois do preenchimento dos vasos, foram aplicados, à superfície do solo, $50 \mathrm{~mL}$ por vaso de solução de Roundup, diluída em água estéril, de modo a serem obtidas concentrações equivalentes às doses de campo de 1,25, 2,5, 5,0, 7,5 e 10,0 L ha-1; além da preparação de tratamento sem o herbicida, totalizando seis tratamentos. $\mathrm{O}$ experimento foi conduzido em delineamento inteiramente casualizado, com cinco repetições.

Depois de dez dias da aplicação do herbicida ao solo, a soja foi semeada (cinco sementes por vaso, desinfestadas com hipoclorito de sódio 1\%), tendo sido inoculado $0,2 \mathrm{~mL}$ da suspensão de células de B. elkanii, estirpe BR 29, em cada semente, totalizando $1 \mathrm{~mL}$ de suspensão de células por vaso. Aos 13 dias depois da emergência (DAE), foi realizado o desbaste, deixandose uma planta por vaso.

Todos os tratamentos receberam, de forma parcelada, aos 14, 21 e $28 \mathrm{DAE}$, um total de $225 \mathrm{mg}$ por vaso de $\mathrm{K}$, na forma de $\mathrm{KH}_{2} \mathrm{PO}_{4}$, e $375 \mathrm{mg}$ por vaso de $\mathrm{P}$, na forma de $\mathrm{H}_{3} \mathrm{PO}_{4}$. Aos 17, 31 e $45 \mathrm{DAE}$, as plantas foram cortadas rente ao solo, tendo as partes aéreas secadas em estufa de circulação de ar a $60^{\circ} \mathrm{C}$ até peso constante, quando o peso da matéria seca foi determinado. As raízes foram lavadas em água corrente e, em seguida, foi feito o destaque e a contagem do número de nódulos. Determinou-se também o peso de raízes e nódulos secos das plantas. Cerca de $1 \mathrm{~g}$ de raízes finas foi retirado de cada planta, para clarificação (Phillipis \& Haymann, 1970) e avaliação da taxa de colonização micorrízica (Giovannetti \& Mosse, 1980).

Os dados de porcentagem de germinação de esporos dos FMA foram normalizados pela transformação arc sen (\% germinação/100) $)^{0,5}$, e os de crescimento do tubo germinativo (CTG) pela transformação $(\mathrm{CTG}+0,5)^{0,5}$. Os resultados de colonização micorrízica foram transformados pelo arc sen (colonização/100) $)^{0,5} \mathrm{e}$ nodulação por (no de nódulos $+0,5)^{0,5}$, respectivamente. Todos os dados foram submetidos à análise de variância e teste de média Tukey a 5\% de probabilidade pelo SISVAR (Ferreira, 2000).

\section{Resultados e Discussão}

Observaram-se, no crescimento bacteriano, efeitos significativos do Roundup influenciados pelas concentrações do herbicida e diferenciados para as estirpes. No primeiro experimento, transcorridas 120 horas, as estirpes BR 29 e INPA 553A apresentaram ligeiro estímulo no crescimento, em concentrações baixas do herbicida, não tendo sofrido elevada inibição em doses elevadas (Figura 1), com crescimento máximo obtido nas concentrações de 89,47 e 86,21 $\mu \mathrm{M}$ de glifosato, respectivamente para essas estirpes. Tais concentrações são cerca de 12 vezes superior à concentração esperada no solo, para doses recomendadas de glifosato que, conforme Moorman (1986), é cerca de $7 \mu \mathrm{M}$.

A estirpe BR 86 apresentou a maior sensibilidade ao glifosato, tendo sido observada redução linear do crescimento, em relação à testemunha, com dose de inibição de 50\% ( $\left.\mathrm{DI}_{50}\right)$ no crescimento em 210,26 $\mu \mathrm{M}$ de glifosato. A estirpe INPA 80A foi insensível ao herbicida, não tendo sofrido influência significativa das doses aplicadas. 
A resposta quadrática do crescimento, observada para as estirpes BR 29 e INPA 553A, corroboram o que é relatado por Eberbach \& Douglas (1989) para outras estirpes, quanto ao benefício do glifosato em baixas concentrações. Entretanto, esses autores verificaram que a partir de concentrações de $10 \mathrm{mg} \mathrm{L}^{-1}$ de i.a. $(59,2 \mu \mathrm{M})$, houve acentuada redução no crescimento de Rhizobium trifolii.

Recentemente, Santos et al. (2004), também observaram um melhor desempenho da estirpe BR 29 (B. elkanii), em relação a outra estirpe de B. elkanii (SEMIA 587) e a uma estirpe de B. japonicum (SEMIA 5079), quando as bactérias foram cultivadas em meio YM adicionado de 43,2 $\mu$ M de Roundup, confirmando a elevada capacidade da estirpe BR 29 em tolerar condições estressantes. No entanto, os efeitos inibitórios, relatados por Santos et al. (2004), foram observados em concentrações de glifosato muito menores do que as usadas neste trabalho. Os ensaios de Santos et al. (2004) foram realizados em condições experimen-
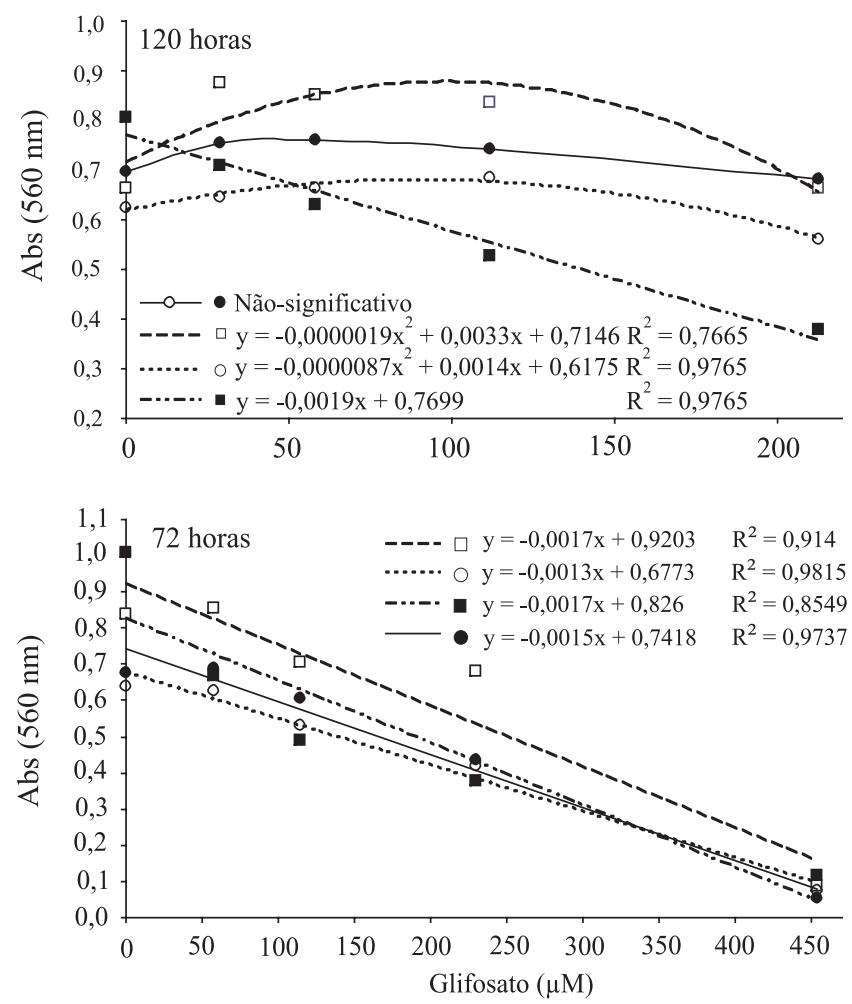

Figura 1. Evolução da densidade ótica das suspensões bacterianas ( $\square$ BR 29; $\square$ BR 86; • INPA 80A; O INPA 553A), com 120 e 72 horas de crescimento, no primeiro e segundo experimentos, respectivamente, em função do aumento da dosagem do glifosato no meio de cultura. tais muito distintas: em placas de Elisa, em que o volume de meio é bastante reduzido $(180 \mu \mathrm{L}$ de meio mais $60 \mathrm{~mL}$ de solução de herbicida) e com diferente proporção inóculo/meio (15 $\mu \mathrm{L}$ de inoculo). Liu et al. (1991) também observaram efeito negativo do glifosato no meio, para a estirpe RM1021 de Rhizobium meliloti, porém em concentração maior que $1.000 \mu \mathrm{M}$, que é muito elevada, quando se considera que a concentração esperada no solo com aplicação de dosagens recomendadas é da ordem de $7 \mu \mathrm{M}$.

O comportamento observado para a estirpe INPA 80A é semelhante ao obtido por Moorman (1986), que também verificou baixa sensibilidade de duas estirpes de Rhizobium japonicum (B. japonicum), cultivadas em meio de cultura com até $20 \mathrm{mg} \mathrm{L}^{-1}(118,3 \mu \mathrm{M})$ de glifosato. Resultados semelhantes são relatados por Mallik \& Tesfai (1983), que não constataram o efeito inibitório do glifosato no número de colônias formadas, da estirpe 3I1b110 de Rhizobium japonicum (B. japonicum), em meio de cultura com até $25 \mu \mathrm{g} \mathrm{mL}^{-1}(147,9 \mu \mathrm{M})$ do glifosato. O mesmo foi observado por Faizah et al. (1980), para três isolados de rizóbio originários da Malásia, África e Austrália. No entanto, esses resultados foram observados apenas durante 24 horas depois da inoculação.

O bom desempenho das estirpes INPA 80A e INPA 553A, de certa forma, não era esperado, pois em razão de as bactérias terem sido isoladas de solos da Região Amazônica, local onde é menor o convívio desses organismos com pesticidas como o Roundup, acreditava-se que, pela inexistência de um processo adaptativo das novas condições impostas, uma maior sensibilidade dessas bactérias à molécula herbicida fosse ocorrer.

Avaliando-se, em um segundo experimento, concentrações mais elevadas do Roundup no meio, até $454 \mu \mathrm{M}$, observaram-se respostas inibitórias e lineares com a elevação nas concentrações de glifosato, depois de 72 horas de cultivo, para todas as estirpes avaliadas (Figura 1). Baseando-se na $\mathrm{DI}_{50}$ calculada, foram constatados valores de 240 a $270 \mu \mathrm{M}$ de glifosato, concentrações estas muito elevadas em relação às normalmente encontradas nos solos. Na concentração máxima avaliada, nenhum crescimento foi observado para as quatro estirpes.

A adição de Roundup ao meio com ágar teve efeito significativo na germinação e no crescimento do tubo germinativo dos esporos de FMA (Figura 2). Verificouse pequeno estímulo do glifosato na germinação de esporos de G. margarita, que atingiu o máximo na concentração de $111,75 \mu \mathrm{M}$. Por outro lado, a 
germinação dos esporos de S. heterogama e G. etunicatum sofreram inibição linear com o aumento das concentrações. No entanto, essas espécies apresentaram comportamentos distintos, como revela a $\mathrm{DI}_{50}$, que foi de 322,9 e $53,6 \mu \mathrm{M}$, respectivamente, para S. heterogama e G. etunicatum, tendo sido este último muito sensível ao glifosato.

$\mathrm{O}$ crescimento do tubo germinativo dos esporos germinados foi igualmente inibido pelo glifosato (Figura 2), tendo obedecido à mesma ordem dos efeitos observados para germinação. Destaca-se a alta sensibilidade do G. etunicatum. Os resultados mostram que as espécies azigospóricas (G. margarita e S. heterogama) foram mais tolerantes que a clamidospórica, aqui representada pelo G. etunicatum. Como esta é a espécie de Glomus de maior ocorrência nos agrossistemas com culturas anuais, no Sudeste brasileiro (Siqueira et al., 1989), o uso generalizado do glifosato pode causar mu-
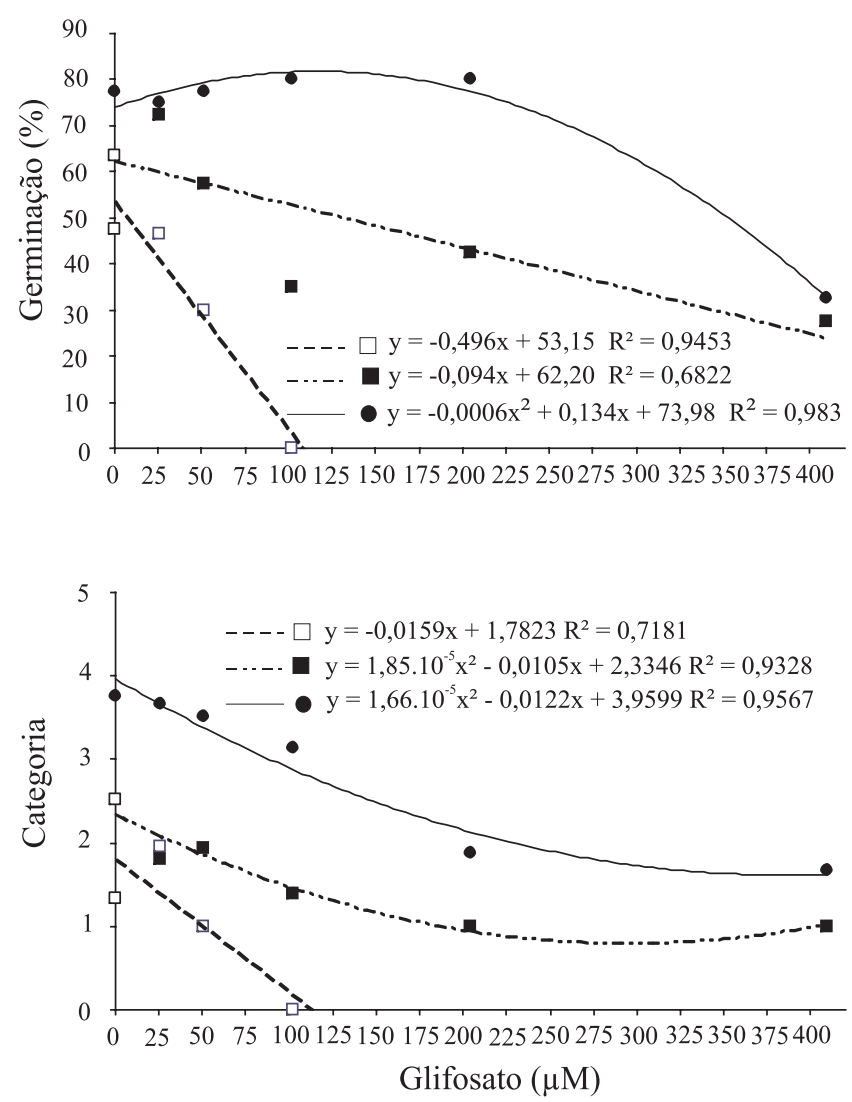

Figura 2. Curvas de regressão linear das porcentagens de germinação e das médias dos valores, das classes atribuídas ao tamanho dos tubos germinativos dos esporos dos fungos micorrízicos arbusculares $(\bigcirc:$ G. margarita; $\mathbf{\square}$ : S. heterogama; e $\square$ : G. etunicatum), em meio ágar-água, com doses crescentes de glifosato. danças nas populações dos FMA nessa região. No entanto, considerando-se a concentração de $7 \mu \mathrm{M}$ de glifosato e as equações de regressão de cada espécie fúngica, verifica-se que as inibições na germinação e no crescimento dos tubos germinativos desses fungos são negligíveis.
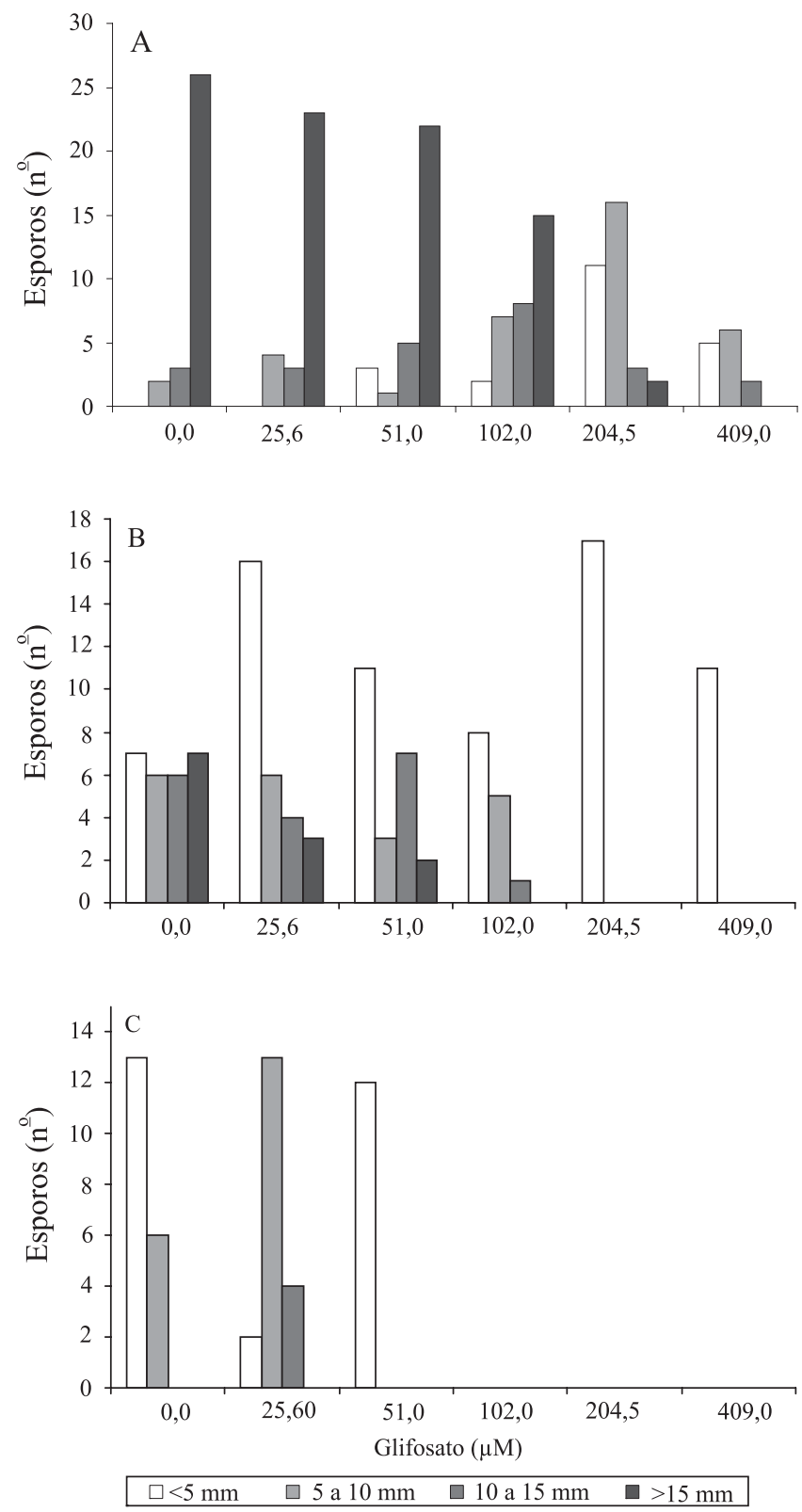

Figura 3. Distribuição dos esporos germinados de Gigaspora margarita (A), Scutellospora heterogama (B) e Glomus etunicatum (C), por categorias de crescimento (1: $<5 \mathrm{~mm} ; 2$ : 5 a $10 \mathrm{~mm}$; 3: 10 a $15 \mathrm{~mm}$ e 4: >15 mm), cultivados em meio ágar-água, com doses crescentes de glifosato. 
O Roundup influenciou, também, o padrão de crescimento dos esporos que germinaram (Figura 3). Para G. margarita, a incidência de esporos com grande crescimento do tubo germinativo foi alta até a concentração de $102 \mu \mathrm{M}$, fato este não observado para as outras duas espécies. Os esporos de S. heterogama e de G. etunicatum, que germinaram em meio com glifosato, praticamente não cresceram, evidenciando maior efeito inibitório do herbicida nessas espécies, em comparação aos esporos de G. margarita. Como o crescimento do tubo germinativo tem relação com a formação de micorrizas, a inibição destes implica em baixa capacidade de colonização das raízes.

No experimento com soja, verificou-se boa nodulação e colonização micorrízica das raízes e crescimento adequado da planta, em todos os tratamentos avaliados. A aplicação prévia de doses crescentes de Roundup, equivalente a até $10 \mathrm{~L} \mathrm{ha}^{-1}(22,5 \mu \mathrm{M})$, não teve efeito significativo no crescimento, na nodulação e na colonização micorrízica da soja, nas três épocas de avaliação do experimento (Tabela 1). Para o peso da matéria seca da raiz, também não foi observado efeito do herbicida nas duas primeiras épocas de avaliação.

Tabela 1. Massa de matéria seca da parte aérea, número de nódulos, matéria seca de nódulos e porcentagem de colonização micorrízica em plantas de soja, aos 17, 31 e 45 dias depois da emergência (DAE), submetidas aos tratamentos com aplicação de doses crescentes de Roundup e respectiva probabilidade $(\mathrm{Pr}>\mathrm{Fc})$.

\begin{tabular}{|c|c|c|c|}
\hline Variável & $17 \mathrm{DAE}$ & $31 \mathrm{DAE}$ & $45 \mathrm{DAE}$ \\
\hline & \multicolumn{3}{|c|}{ Matéria seca da parte aérea (g) } \\
\hline Doses de Roundup & 0,32 & 1,42 & 4,78 \\
\hline $\operatorname{Pr}>\mathrm{Fc}$ & $0,22^{\mathrm{ns}}$ & $0,42^{\mathrm{ns}}$ & $0,34^{\mathrm{ns}}$ \\
\hline \multirow[t]{2}{*}{$\mathrm{CV}(\%)$} & 17,96 & 21,91 & 10,09 \\
\hline & \multicolumn{3}{|c|}{ Número de nódulos } \\
\hline Doses de Roundup & - & 46,50 & 127,00 \\
\hline $\operatorname{Pr}>\mathrm{Fc}$ & - & $0,49^{\mathrm{ns}}$ & $0,36^{\mathrm{ns}}$ \\
\hline \multirow[t]{2}{*}{$\mathrm{CV}(\%)$} & - & 15,32 & 13,60 \\
\hline & \multicolumn{3}{|c|}{ Matéria seca de nódulos (g) } \\
\hline Doses de Roundup & - & 0,02 & 0,26 \\
\hline $\operatorname{Pr}>\mathrm{Fc}$ & - & $0,50^{\mathrm{ns}}$ & $0,53^{\mathrm{ns}}$ \\
\hline \multirow[t]{2}{*}{$\mathrm{CV}(\%)$} & - & 35,73 & 25,97 \\
\hline & \multicolumn{3}{|c|}{ Colonização micorrízica (\%) } \\
\hline Doses de Roundup & 44,00 & 77,00 & 80,00 \\
\hline $\operatorname{Pr}>\mathrm{Fc}$ & $0,15^{\mathrm{ns}}$ & $0,93^{\mathrm{ns}}$ & $0,64^{\mathrm{ns}}$ \\
\hline $\mathrm{CV}(\%)$ & 16,57 & 11,37 & 9,56 \\
\hline
\end{tabular}

${ }^{\text {ns Não-significativo. }}$
Apesar do efeito inibitório, observado na germinação e no crescimento dos esporos no experimento in vitro, não houve efeito do glifosato na colonização, nas condições experimentais avaliadas. Morandi (1989) verificou que a colonização da soja por Glomus mosseae foi favorecida pela aplicação de glifosato $\left(0,5 \mu \mathrm{g} \mathrm{mL}^{-1}=2,9 \mu \mathrm{M}\right)$, depois da emergência das plantas. $\mathrm{O}$ autor sugere que esse efeito positivo do glifosato pode resultar da maior produção de isoflavonóides nas raízes, os quais podem promover a colonização micorrízica, conforme relatado por Siqueira et al. (1991). A ausência de efeito do glifosato na nodulação é coerente com o que tem sido relatado para dosagens normais. Mallik \& Tesfai (1985) observaram redução do número e do peso dos nódulos, com a aplicação de até cinco vezes a dose recomendada do herbicida $(35 \mu \mathrm{M}), 17$ dias depois da semeadura da soja. Ao trabalhar com variedades de soja geneticamente modificadas para tolerar o glifosato, King et al. (2001) verificaram efeitos inconsistentes do glifosato na nodulação. Como o glifosato atua na síntese de aminoácidos precursores dos flavonóides, é de se esperar que a aplicação desse produto à soja interfira na nodulação, entretanto, como avaliado neste trabalho com soja convencional, a aplicação prévia do herbicida não teve esse tipo de efeito.

\section{Conclusões}

1. A inibição no crescimento de Bradyrhizobium spp., em meio de cultura, varia em razão das estirpes estudadas e só ocorre em concentração muito superior àquelas normalmente utilizadas em condições reais de campo; a estirpe de B. japonicum (BR 86) apresenta maior sensibilidade que as estirpes de B. elkanii (BR 29, INPA 80A e INPA 553A).

2. A germinação e o crescimento dos tubos germinativos dos esporos, das espécies de FMA, em ágar-água, mostram comportamento diferente em relação às doses de glifosato; Glomus etunicatum é sensível, Gigaspora margarita é tolerante e Scutellospora heterogama tem comportamento intermediário.

3. A aplicação prévia de Roundup ao solo, até a dose equivalente a $10 \mathrm{~L} \mathrm{ha}^{-1}$, não influencia na nodulação e na colonização micorrízica da soja.

\section{Agradecimentos}

À Capes e ao CNPq, pelas bolsas concedidas. 


\section{Referências}

BUSSE, M.D.; RATCLIFF, A.W.; SHESTAK, C.J.; POWERS, R.F. Glyphosate toxicity and the effects of long-term vegetation control on soil microbial communities. Soil Biology and Biochemistry, v.33, p.1777-1789, 2001.

COX, C. Glyphosate factsheet. Journal of Pesticide Reform, v.108, 1998, rev. 2000.

EBERBACH, P.L.; DOUGLAS, L.A. Herbicide effects on the growth and nodulation potential of Rhizobium trifolii with Trifolium subterraneum L. Plant and Soil, v.119, p.15-23, 1989.

FAIZAH, A.W.; BROUGHTON, W.J.; JOHN, C.K. Rhizobia in tropical legumes. XI. Survival in the seed environment. Soil Biology and Biochemistry, v.12, p.219-227, 1980.

FERREIRA, D.F. Análises estatísticas por meio do Sisvar para Windows versão 4.0. In: REUNIÃO ANUAL DA REGIÃO BRASILEIRA DA SOCIEDADE INTERNACIONAL DE BIOMETRIA, 45., 2000, São Carlos. Anais. São Carlos: Ufscar, 2000. p.255-258.

FRED, E.B.; WAKSMAN, S.A. Laboratory manual of general microbiology. New York: McGraw-Hill, 1928. 145p.

GERDEMANN, J.W.; NICOLSON, T.H. Spores of mycorrhizal Endogone species extracted from soil wet sieving and decanting. Transactions of British Mycological Society, v.46, p.235-244, 1963.

GIOVANNETTI, M.; MOSSE, B. An evaluation of techniques for measuring vesicular-arbuscular mycorrhizal infection on roots. New Phytologist, v.84, p.489-500, 1980.

GORLACH-LIRA, K.; STEFANIAK, O.; SLIZAK, W.; OWEDYK, I. The response of forest soil microflora to the herbicide formulations Fusilade and Roundup. Microbiological Research, v.152, p.319329, 1997.

HAAHTELA, K.; KILPI, S.; KARI, K. Effects of phenoxy acid herbicides and glyphosate on nitrogenase activity (acetylene reduction) in root-associated Azospirillum, Enterobacter and Klebsiella. FEMS Microbiology Letters, v.53, p.123-127, 1988.

KING, C.A.; PURCELL, L.C.; VORIES, E.D. Plant growth and nitrogenase activity of glyphosate-tolerant soybean in response to foliar glyphosate applications. Agronomy Journal, v.93, p.179186, 2001.

LIU, C.-M.; McLEAN, P.A.; SOOKDEO, C.C.; CANNON, F.C. Degradation of the herbicide glyphosate by members of the family Rhizobiaceae. Applied and Environmental Microbiology, v.57, p.1799-1804, 1991.

MALLIK, M.A.B.; TESFAI, K. Compatibility of Rhizobium japonicum with commercial pesticides in vitro. Bulletin of Environmental Contamination and Toxicology, v.31, p.432-437, 1983.
MALLIK, M.A.B.; TESFAI, K. Pesticidal effect on soybean-rhizobia symbiosis. Plant and Soil, v.85, p.33-41, 1985.

MÅRTENSSON, A.M. Effects of agrochemicals and heavy metals on fast-growing rhizobia and their symbiosis with small-seeded legumes. Soil Biology and Biochemistry, v.24, p.435-445, 1992. MOORMAN, T.B. Effects of herbicides on the survival of Rhizobium japonicum strains. Weed Science, v.34, p.628-633, 1986.

MOORMAN, T.B.; BECERRIL, J.M.; LYDON, J.; DUKE, S.O. Production of hydroxybenzoic acids by Bradyrhizobium japonicum strains after treatment with glyphosate. Journal of Agricultural and Food Chemistry, v.40, p.289-293, 1992.

MORANDI, D. Effect of xenobiotics on endomycorrhizal infection and isoflavonoid accumulation in soybean roots. Plant Physiology and Biochemistry, v.27, p.697-701, 1989.

MOREIRA, F.M.S.; HAUKKA, K.; YOUNG, J.P.W. Biodiversity of rhizobia isolated from a wide range of forest legumes in Brazil. Molecular Ecology, v.7, p.889-895, 1998.

PHILLIPS, J.M.; HAYMAN, D.S. Improved procedures for cleaning roots and staining parasitic and vesicular-arbuscular mycorrhizal fungi for rapid assessment of infection. Transactions of the British Mycological Society, v.55, p.158-161, 1970.

QUINN, J.P.; PEDEN, J.M.M.; DICK, R.E. Glyphosate tolerance and utilization by the microflora of soils treated with the herbicide. Applied Microbiology and Biotechnology, v.29, p.511-516, 1988.

ROSLYCKY, E.B. Glyphosate and the response of the soil microbiota. Soil Biology and Biochemistry, v.14, p.87-92, 1982.

SANTOS, A.; FLORES, M. Effects of glyphosate on nitrogen fixation of free-living heterotrophic bacteria. Letters in Applied Microbiology, v.20, p.349-352, 1995.

SANTOS, J.B.; JACQUES, R.J.S.; PROCÓPIO, S.O.; KASUYA, M.C.M.; SILVA, A.A.; SANTOS, E.A. Efeitos de diferentes formulações comerciais de glyphosate sobre estirpes de Bradyrhizobium. Planta Daninha, v.22, p.293-299, 2004.

SIQUEIRA, J.O.; COLOZZI-FILHO, A.; OLIVEIRA, E. de. Ocorrência de micorrizas vesicular-arbusculares em agroecossistemas do Estado de Minas Gerais. Pesquisa Agropecuária Brasileira, v.24, p.1499-1506, 1989.

SIQUEIRA, J.O.; SAFIR, G.R.; NAIR, M.G. Stimulation of vesicular-arbuscular mycorrhiza formation and growth of white clover by flavonoid compounds. New Phytologist, v.118, p.87-93, 1991.

SIQUEIRA, J.O.; TRANNIN, I.C. de B.; RAMALHO, M.A.P.; FONTES, E.M.G. Interferências no agrossistema e riscos ambientais de culturas transgênicas tolerantes a herbicidas e protegidas contra insetos. Cadernos de Ciência e Tecnologia, v.21, p.11-81, 2004. WARDLE, D.A.; PARKINSON, D. Influence of the herbicide glyphosate on soil microbial community structure. Plant and Soil, v.122, p.29-37, 1990.

WARDLE, D.A.; PARKINSON, D. Relative importance of the effect of 2,4-D, glyphosate, and environmental variables on the soil microbial biomass. Plant and Soil, v.134, p.209-219, 1991.

$\overline{\text { Recebido em } 13 \text { de dezembro de } 2004 \text { e aprovado em } 2 \text { de julho de } 2005}$ 